\title{
Hemispherical DRA Antennas Mounted on or Embedded in Circular Cylindrical Surface for Producing Omnidirectional Radiation Pattern
}

\author{
Saber H. Zainud-Deen ${ }^{1}$, Noha A. El-Shalaby ${ }^{2}$, Kamal H. Awadalla ${ }^{1}$ \\ ${ }^{1}$ Faculty of Electronic Engineering, Menoufia University, Shibin el Kom, Egypt \\ ${ }^{2}$ Faculty of Engineering, Kafrelsheikh University, Kafr el-Sheikh, Egypt \\ E-mail:anssaber@yahoo.com,Noha1511ahm@yahoo.com \\ Received June 29, 2011; revised August 4, 2011; accepted August 20, 2011
}

\begin{abstract}
The radiation characteristics of hemispherical DRA elements mounted on or embedded in a hollow circular cylindrical ground structure are investigated. The performance of the DRA array which operates at about 1.8 $\mathrm{Ghz}$, is studied. Factors influencing the array performance, such as the number of elements and element spacing are explained. The perforated dielectric technique is used to design the array from a single dielectric sheet. The overall profile of the antenna can be significantly reduced. The radiation patterns with respect to the number of DRA elements are depicted.
\end{abstract}

Keywords: DRAs, FEM, FIT

\section{Introduction}

Cylindrical conducting surfaces with antennas fixed on top are widespread in different systems such as aerospace vehicles and satellites In these applications, the antenna radiation pattern is needed to be almost omnidirectional, and the antenna efficiency has to be high [1-4]. The dielectric resonator antenna (DRA) can offer all the requirements for such applications [5-11]. DRA antenna has great flexibility in shape, material and feeding mechanisms. In addition, DRA resonant antennas can have wide bandwidth and large angle of coverage. The radiation characteristics of cylindrical and hemispherical DRAs placed on or embedded in circular cylindrical and spherical ground planes are investigated in [12-15].

In this paper, the performance of the hemispherical DRA array elements mounted on or embedded in circular cylindrical ground plane for producing omnidirectional radiation pattern, which operates at about $1.8 \mathrm{GHz}$, is studied. The array performance is very much influenced by several factors, such as the number of elements and elements spacing. These effects have been investigated in this work. The perforated dielectric technique is used to design the array from a single dielectric sheet. The overall profile of the antenna can be significantly reduced. The perforation is implemented as a uniform lat- tice of holes drilled through dielectric links that help in fixing the antenna elements [16]. It can be seen that an increase in the number of hemispherical DRA antennas directly result in a better approximation of an omnidirectional pattern. The hemispherical DRA antenna elements are uniformly distributed along the circumference of a finite hollow conducting cylinder. The radiation patterns with respect to the number of DRA elements are investigated based on the radiation characteristic. It will be seen that an array of eight hemispherical DRAs is a good candidate for omnidirectional pattern. Numerical results are obtained using the finite element method (FEM) and compared with that calculated by the finite integration technique (FIT) for authentication.

\section{Methods of Solution}

\subsection{Finite Element Method}

In this paper, the finite element method (FEM) is used to determine the radiation characteristics of the antennas. The finite element method is quite suitable for the analysis of DRA antennas. The basic idea of the finite element method is to divide the electromagnetic structure in a number of elements which usually have the same shape but can differ in size, as the elements shape could be 
rectangles or triangles for surfaces or cuboids and pyramids for solid objects. The field within each element is expanded in terms of a set of basis functions. These functions are usually weighted and controlled by the field values at the nodes of the element. A matrix equation is then formed, with the field values at the element nodes as the unknowns. Solving this matrix equation the unknowns can be determined [17-24].

\subsection{Finite Integration Technique}

The finite integration technique (FIT) is conceptually different from the FET method. This is why it is used to confirm the accuracy of the results. This method is very versatile and suitable for quite a wide range of electromagnetic problems. The basic idea of this approach is to discretize the application domain in a set of staggered grids and apply Maxwell's equations in the integral form to such grids, so it is called Maxwell-Grid-Equations (MGE). As usual in some of the numerical techniques, the application will end up in matrix equations. The resulting matrix equations of the discretized fields can be used for determining the distribution of the fields in the problem domain. The finite integration technique is relatively faster than other numerical techniques such as the finite difference time domain technique and the FEM mentioned above. It has also relatively high flexibility in modeling different geometric shapes and in handling boundaries. It has to be noted that, from our experience the results determined using the FEM are more accurate than those obtained using the FIT due to the fact that the FIT has to stick to a rectangular or cubical staggered grids which are not adequate in fitting the curved boundaries. More details about FIT can be found in [25-30].

\section{Numerical Results}

\section{An Array of Hemispherical DRAs Mounted on or Embedded in Circular Cylindrical Surface}

Figure 1 shows the array geometry of hemispherical DRA elements which are equally spaced and placed on a circular cylindrical ground plane. The hemispherical DRA with dielectric constant $\varepsilon r=8.9$ is used. It has radius " $a$ ", of $2.54 \mathrm{~cm}$. A coaxial probe with radius of $0.075 \mathrm{~cm}$ excites each element. All the ports of the elements were fed with signals which are in phase and equal in amplitude. The probe is located off the center by $d_{f}=$ $1.74 \mathrm{~cm}$ with a height " $h$ ", of $1.52 \mathrm{~cm}$. The hemispherical DRA is designed to operate at $1.8 \mathrm{GHz}$. $l$ the length of the circular cylindrical ground plane, "lg", is $50 \mathrm{~cm}$. The thickness of the cylindrical conductor is $0.6 \mathrm{~mm}$, and

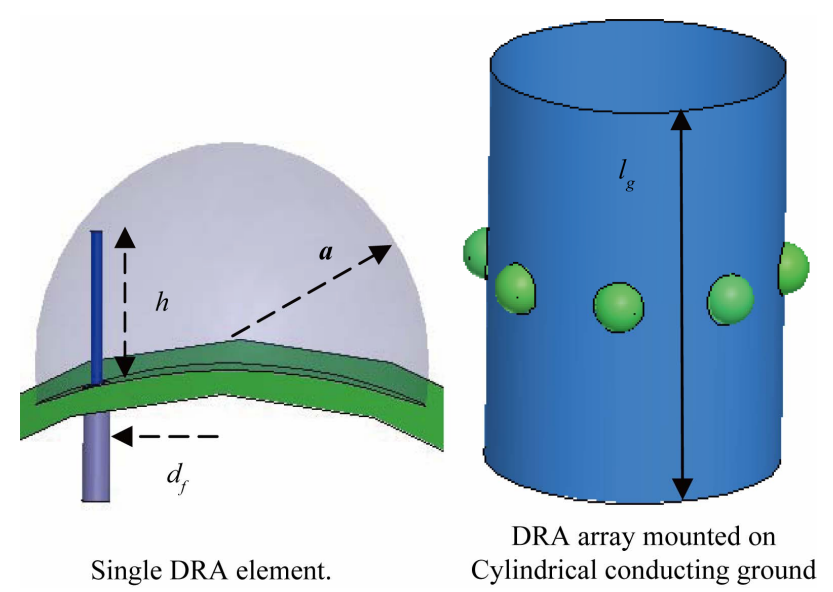

Figure 1. The geometry of hemispherical DRA array mounted on a cylindrical ground.

the radius of the circular cylinder is " $r$ ". The simulated reflection coefficient as a function of frequency and the radiation pattern for one element, and two elements mounted on circular cylindrical ground plane are illustrated in Figure 2. The radius of the circular cylindrical ground is $r_{g}=7.5 \mathrm{~cm}$. The simulated results are calculated by using the FEM and compared with that calculated by FIT method. Good agreement is obtained.

As the resonance frequency is $1.8 \mathrm{GHz}$, i.e. $\lambda=16.67$ $\mathrm{cm}$, which is of the same order of the diameter of the cylindrical ground plane, thus the back radiation is relatively high. This high backward radiation has revealed itself strongly in the radiation pattern of the single element and also in that of the two oppositely mounted elements. The results indicate clearly that the backward radiation is not in phase with the forward radiation of the other element which causes lower forward and backward radiation, i.e. $0^{\circ}$ and $180^{\circ}$ directions, than the in-phase radiation at $90^{\circ}$ and $270^{\circ}$ directions. In the same time, the antenna bandwidth for the two element array has gone down due to the effect of the other elements as seen from the behavior of the reflection coefficient.

The radiation patterns with respect to the number of DRA elements array are investigated by using FIT and compared with FEM. Good agreement is obtained. It can be seen that increasing the number of DRA elements in the array result in a better approximation for an omnidirectional pattern. When the numbers of DRA elements are increased to five elements the ripple in the radiation pattern is $7 \mathrm{~dB}$. For six hemispherical DRA elements, the ripple in the radiation pattern is reduced to be $2 \mathrm{~dB}$ as shown in Figure 3. However, increasing the number of elements brings them closer to each other which result in strong coupling between them. This strong coupling reduces the reflection coefficient bandwidth and causes 

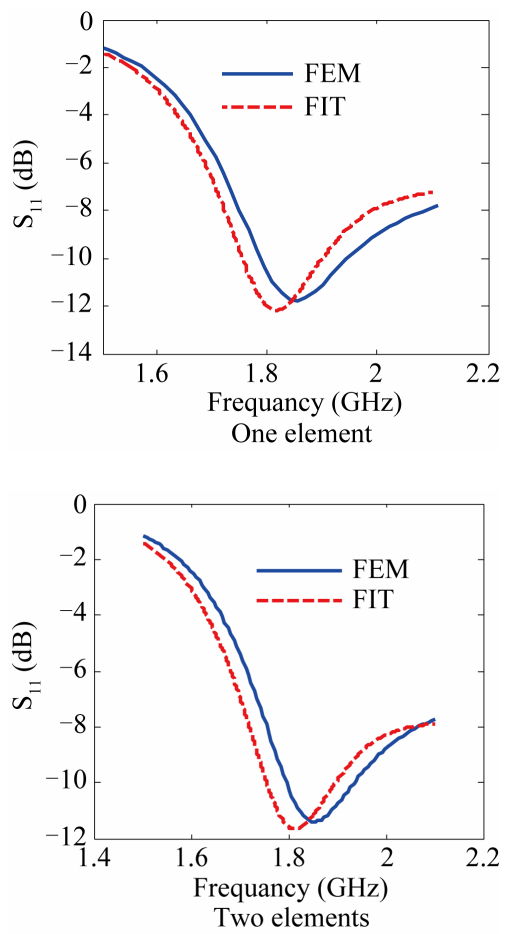

(a)
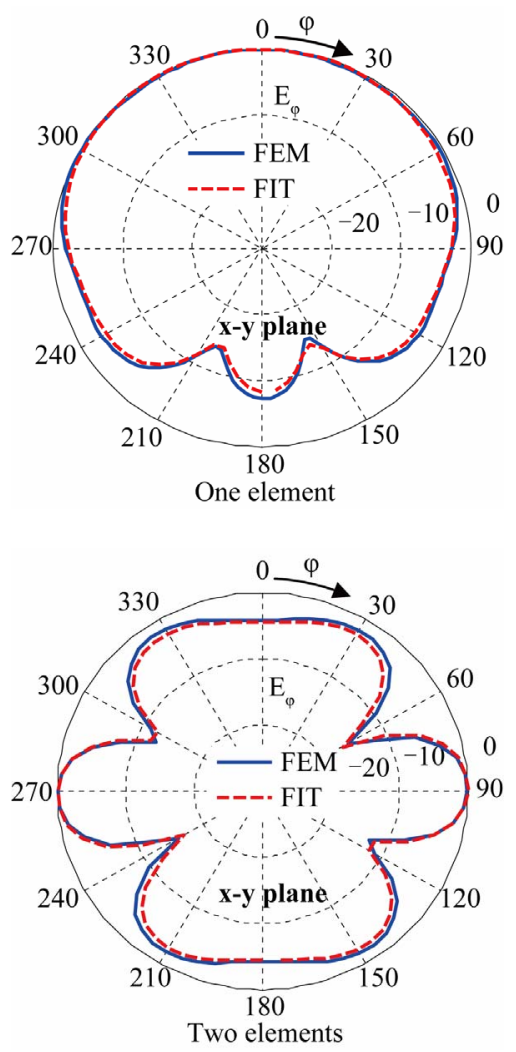

(b)

Figure 2. The reflection coefficient and radiation pattern at $r_{g}=7.5 \mathrm{~cm}$. (a) The reflection coefficient; (b) The radiation patterns.

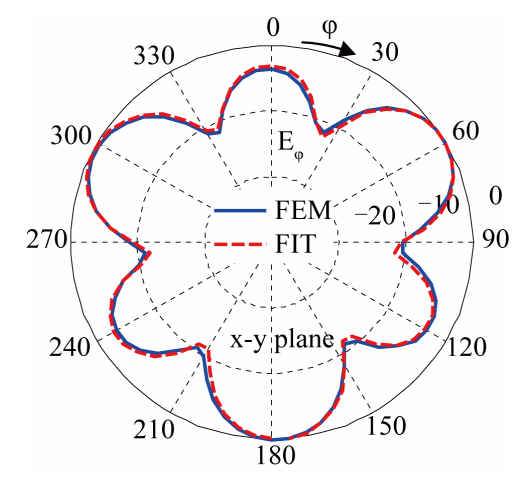

(a)

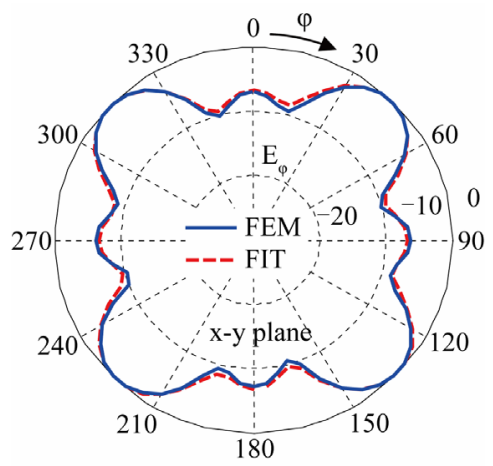

(b)

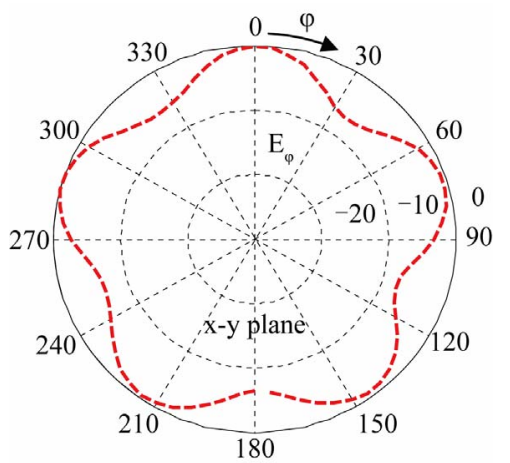

(c)

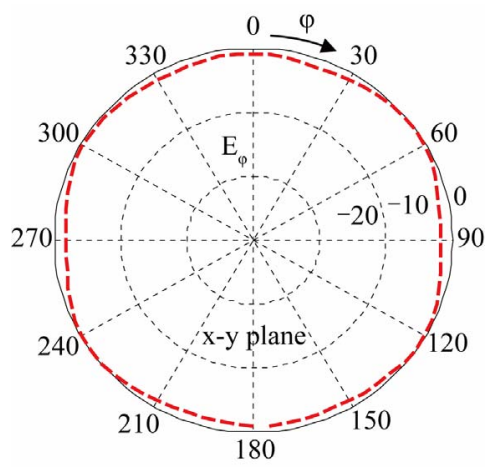

(d)

Figure. 3. The radiation patterns of an array with different elements at $\boldsymbol{r}_{g}=7.5 \mathrm{~cm}$ on cylindrical ground plane. (a) 3 elements; (b) 4 elements; (c) 5 elements; (d) Six elements. 
some difficulty in adjusting the feed for the antenna elements. (It has to be noted that no more than 9 DRA elements can be fixed on the ground plane circumference according to the selected dimensions).

Figure 4 shows the reflection coefficient as a function of frequency for one element, and also for two elements when $r_{g}=15 \mathrm{~cm}$. Increasing the size of the cylindrical ground plane has reduced the level of the diffracted field which forms the back radiation for the single case as in Figure 4(a). It indicates a lower effect of each element on the other's radiation in the front direction. This is of course due to the lower level of the diffracted field. Increasing the number of the elements as in Figures 5(a)-(c) the strong dips in the radiation pattern becomes more diluted. As the number of the DRA elements reaches 8 in this case, the ripple in the radiation pattern is reduced to $3 \mathrm{~dB}$ as shown in Figure 5.

For more economy and for getting rid of the protrusion of the DRA elements, a hemispherical DRA array with elements embedded in cylindrical ground plane structure loaded with protecting dielectric superstrate is proposed as shown in Figure 6. The superstrate layer directly loads the hemispherical DRA. It has a relative permittivity $\varepsilon_{r s}=2.2$, a thickness $h c=27 \mathrm{~cm}$ and $r c=45 \mathrm{~cm}$, as shown in Figure 6. The reflection coefficient and the radiation pattern for one element and three elements is depicted in Figures 7(a) and (b). The results are produced for $r_{g}=15 \mathrm{~cm}$. The radiation patterns for 5 and 8 hemispherical DRA elements are illustrated in Figure 8. The variation in the ripple in the radiation pattern by increasing the number of embedded DRAs is nearly producing similar variations as in the case of protruding elements. But note that impedance bandwidth decreased with embedded DRAs.

Another geometry of DRA array is shown in Figure 9. The perforated dielectric technique is used to design the array from a single dielectric sheet. The spacing and the diameter of holes are used to determine the effective dielectric constant of the material surrounding the DRA elements, the effective dielectric constant, $\varepsilon_{\text {reff, for the }}$ perforated material can be calculated from [16].

$$
\alpha=\frac{\pi R_{h}^{2}}{2(\sqrt{3} / 4) S_{h}^{2}}, \varepsilon_{r e f f}=\varepsilon_{r}(1-\alpha)+\alpha
$$

Where $R_{h}$ is the radius of the air holes, and $S_{h}$ is the center to center separation of the holes. This technique of fabricating the DRA array is more practical, and feasible. The reflection coefficients as a function of frequency for one element and four elements are shown in Figure 10. The radiation patterns in $\mathrm{x}-\mathrm{y}$ plane for one, four and eight elements around the circular cylindrical ground plane of radius $r_{g}=15 \mathrm{~cm}$ are shown in Figures 10 and 11. The ripple in the radiation pattern is reduced by increasing
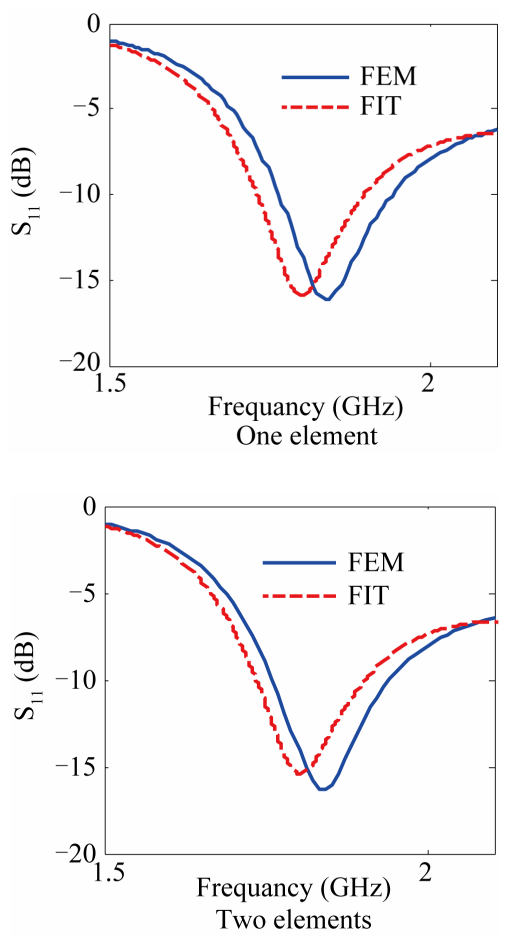

(a)
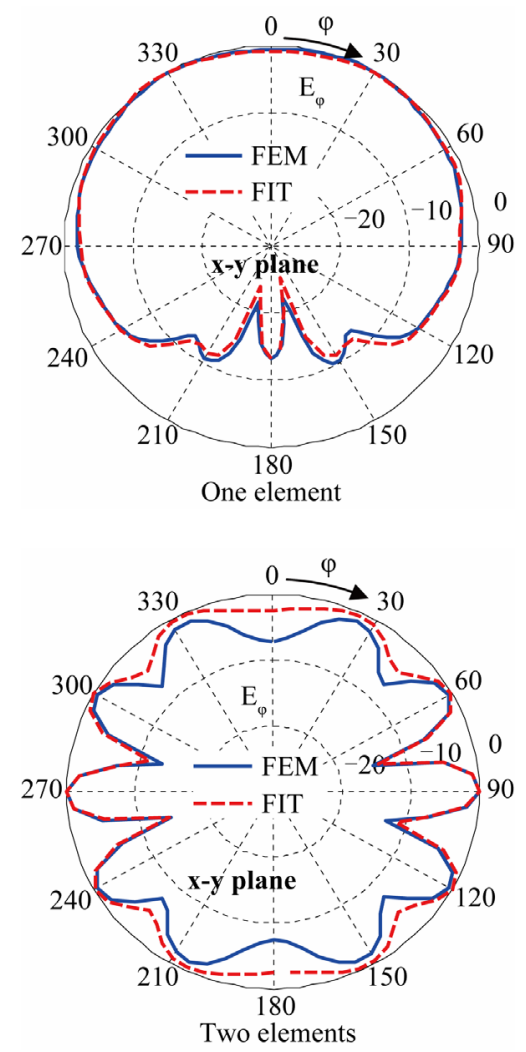

(b)

Figure 4. The reflection coefficient and radiation pattern at $r_{g}=15 \mathrm{~cm}$. (a) The reflection coefficient; (b) The radiation pattern. 


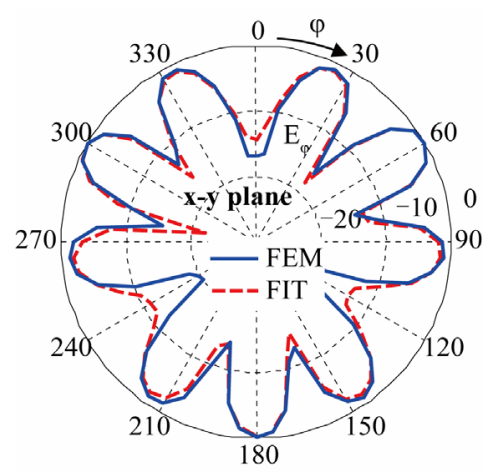

(a)

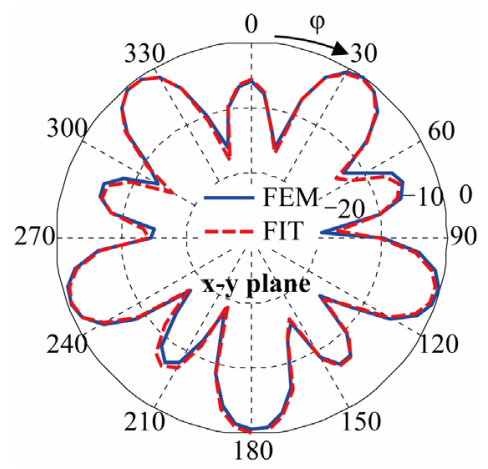

(b)

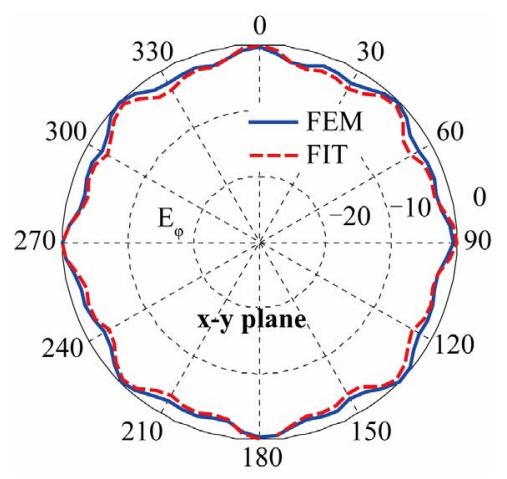

(c)

Figure 5. The radiation patterns of an array with different elements on cylindrical ground plane, at $r_{g}=15 \mathrm{~cm}$. (a) Three elements; (b) Five elements; (c) 8 elements.

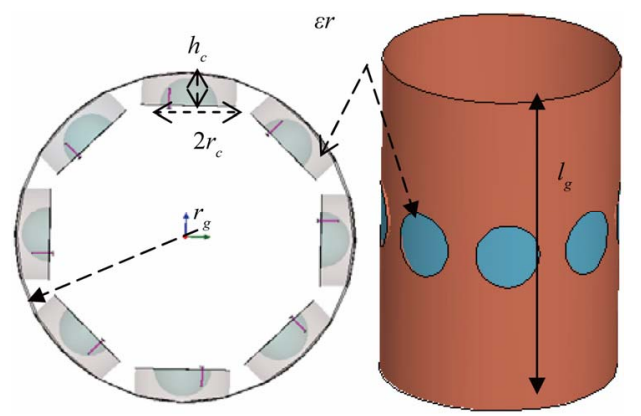

Figure 6. The geometry of hemisphere DRAs array embedded in a cylindrical ground.
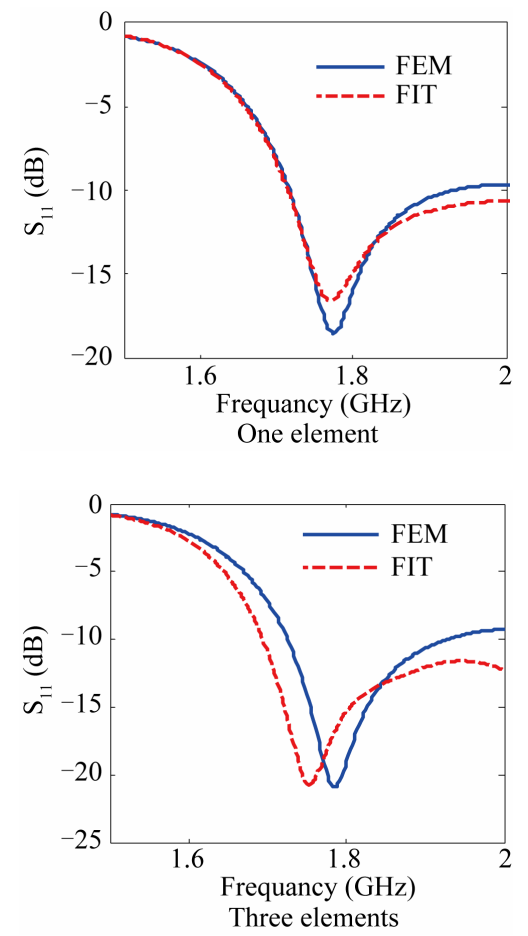

(a)
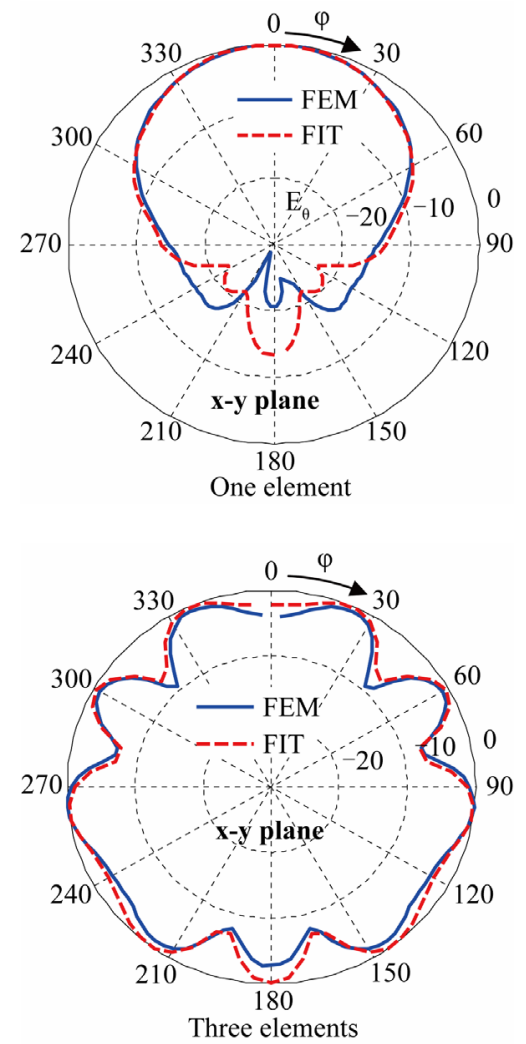

(b)

Figure 7. The reflection coefficient and radiation pattern at $r_{g}=15 \mathrm{~cm}$. (a) The reflection coefficient; (b) The radiation pattern. 


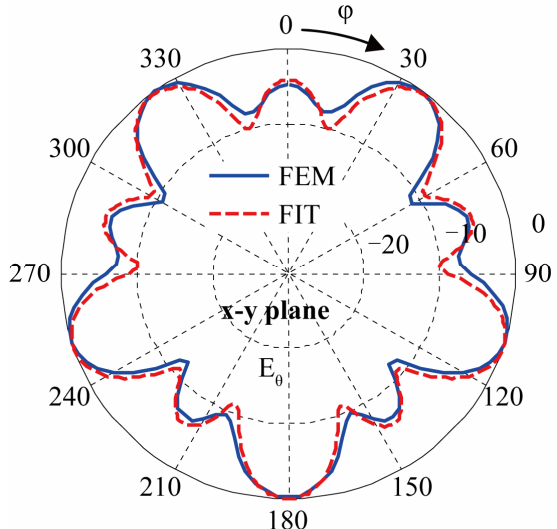

(a)

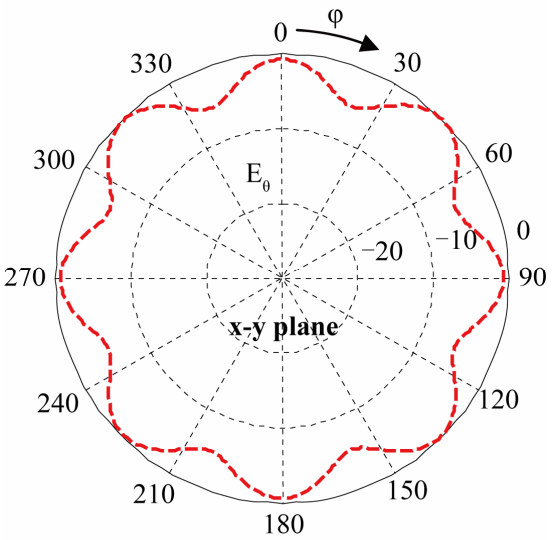

(b)

Figure 8. The radiation patterns of an array with different elements embedded in cylindrical ground plane, $r_{g}=15 \mathrm{~cm}$. (a) Five elements; (b) Eight elements.

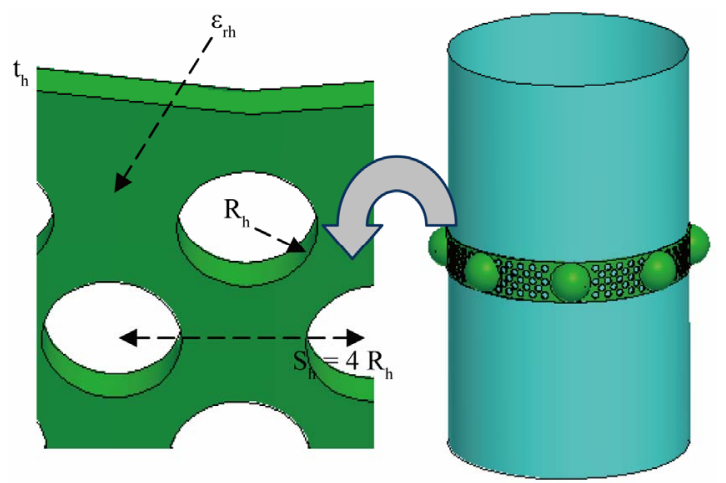

Figure 9. The geometry of hemispherical DRA elements with perforated link on a circular cylindrical ground plane, $r_{g}=15 \mathrm{~cm}, R_{h}=4.23 \mathrm{~mm}, S_{h}=16.92 \mathrm{~mm}, t_{h}=2.032 \mathrm{~mm}$.

the number of DRA elements.

\section{Conclusions}

The performance of a hemispherical DRA antenna mounted
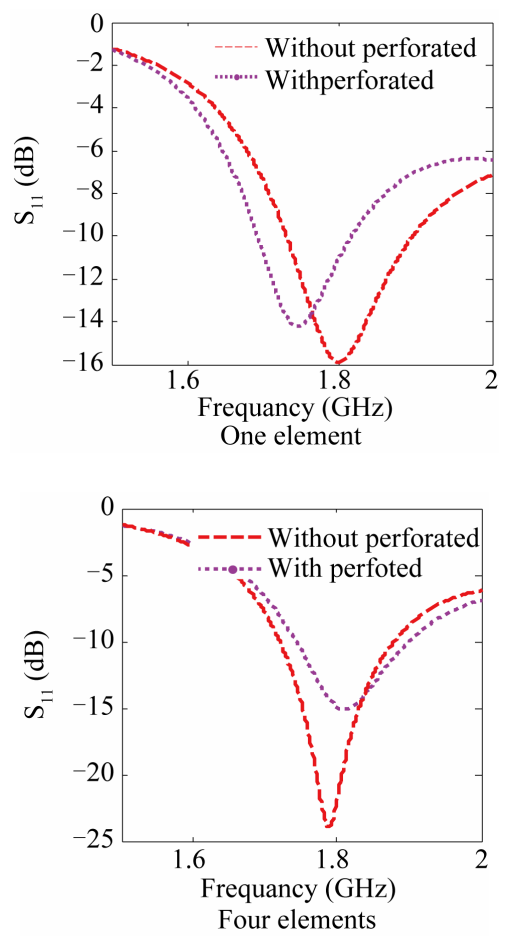

(a)
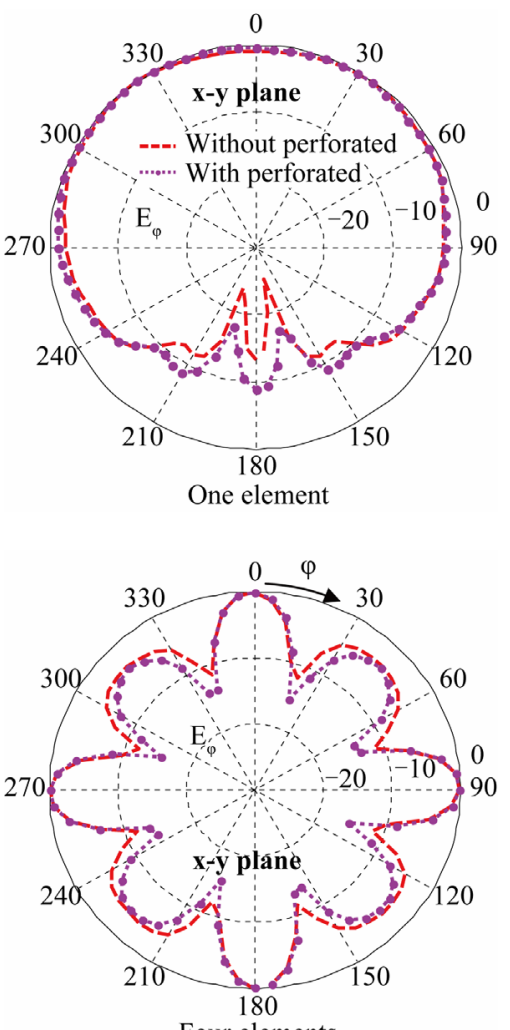

Four elements

(b)

Figure 10. The reflection coefficient and radiation pattern at $r_{g}=15 \mathrm{~cm}$. (a) The reflection coefficient; (b) The radiation pattern. 


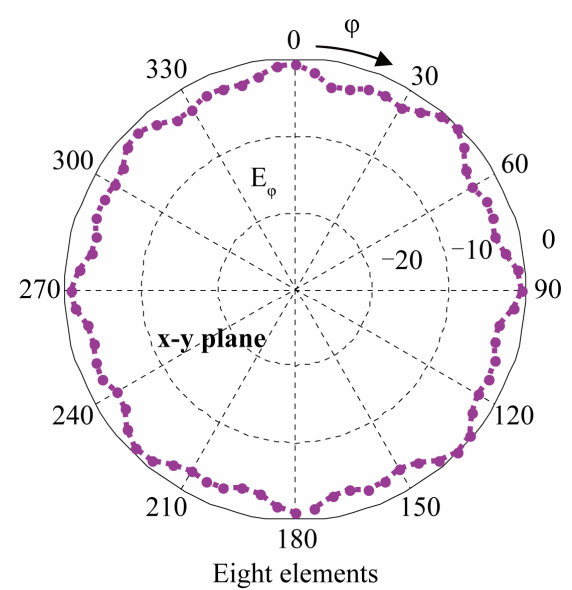

Figure 11. The radiation pattern of perforated antenna array with different number of elements at $r_{g}=15 \mathrm{~cm}$.

on and embedded in a hollow circular cylindrical plane has been demonstrated in this paper. The effects of the cylinder curvature on the radiation pattern, element numbers and element spacing are investigated. Eight hemispherical DRAs have been found to be a good candidate for producing an omnidirectional pattern. A high gain omnidirectional antenna array operating at $1.8 \mathrm{GHz}$ with low gain ripple in the azimuth radiation pattern is achieved by different structures.

\section{References}

[1] D. Uffler, E. Gschwendtner and W. Wiesbeck, "Design and Measurement of Conformal Antennas on Cylindrical and Spherical Geometries," IEEE Transactions on Antennas and Propagation, Vol. 2, No. 2, June 1999, pp. 1005-1010.

[2] P. Li, K. M. Luk and K. L. Lau, "An Omnidirectional High Gain Microstrip Antenna Array Mounted on a Circular Cylinder," IEEE Transactions on Antennas and Propagation, Vol. 4, No. 1, June 2003, pp. 698-701.

[3] M. Keskilammi and M. Kivikoski, "Cylindrical Patch Antenna Array for RFID Applications," Tampere University of Technology, Tampere.

[4] Z. Zhang, X. Gao, W, Chen, Z. Feng and M. F. Iskander, "Study of Conformal Switchable Antenna System on Cylindrical Surface for Isotropic Coverage," IEEE Transactions on Antennas and Propagation, Vol. 59, No. 3, March 2011, pp. 776-783. doi:10.1109/TAP.2010.2103041

[5] K. Luk and K. W. Leung, "Dielectric Resonator Antenna," Research Studies Press, Hertfordshire, 2003.

[6] G. C. Almpanis, C. Fumeaux, and R. Vahldieck, "The Trapezoidal Dielectric Resonator Antenna," IEEE Transactions on Antennas and Propagation, Vol. 56, No. 9, September 2008, pp. 2810-2816. doi:10.1109/TAP.2008.928787

[7] G. P. Junker, A. A. Kishk and A. W. Glisson, "Input Impedance of Dielectric Resonator Antenna Excited by a
Coaxial Probe," IEEE Transactions on Antennas and Propagation, Vol. 42, No. 7, July 1994, pp. 960-966. doi: $10.1109 / 8.299598$

[8] A. A. Kishk, Y. Yin and A. W. Glisson, "Conical Dielectric Resonator Antennas for Wideband Applications," IEEE Transactions on Antennas and Propagation, Vol. 50, No. 4, April 2002, pp. 469-474. doi:10.1109/TAP.2002.1003382

[9] B. Li and K. W. Leung, "On the Differentially Fed Rectangular Dielectric Resonator Antenna," IEEE Transactions on Antennas and Propagation, Vol. 56, No. 2, February 2008, pp. 353-359.

[10] T.-H. Chang and J.-F. Kiang, "Sectorial-Beam Dielectric Resonator Antenna for WiMAX with Bent Ground Plane," IEEE Transactions on Antennas and Propagation, Vol. 57, No. 2, February 2009, pp. 563-572. doi:10.1109/TAP.2008.2011408

[11] A. Petosa, "Dielectric Resonator Antenna Handbook," Artech House, Inc., Norwood, 2007.

[12] S. H. Zainud-Deen, H. A. Malhat and K. H. Awadalla, "Dielectric Resonator Antenna Mounted on a Circular Cylindrical Ground Plane," Progress in Electromagnetics Research B, PIER B, Vol. 19, 2010, pp. 427-444.

[13] S. H. Zainud-Deen, H. A. Malhat and K. H. Awadalla, "Cylindrical Dielectric Resonator Antenna Housed in a Shallow Cavity in a Hollow Circular Cylindrical Ground Plane," 26th Applied Computational Electromagnetic Society (ACES) Conference, Tampere, 26-29 April 2010.

[14] S. H. Zainud-Deen, N. A. El-Shalaby and K. H. Awadalla, "Radiation Characteristics of Cylindrical Dielectric Resonator Antenna Mounted on Superquadric Cylindrical Body," 27th Applied Computational Electromagnetics Society (ACES) Conference, Williamsburg, 27-31 March 2011.

[15] S. H. Zainud-Deen, N. A. El-Shalaby and K. H. Awadalla, "Hemispherical Dielectric Resonator Antenna Mounted on or Embedded in Spherical Ground Plane with a Superstrate," 28th National Radio Science Conference (NRSC 2011), National Telecommunication Institute, Cairo, 15 March 2011.

[16] Y. Zhang and A. A. Kishk, "Analysis of Dielectric Resonator Antenna Arrays with Supporting Perforated Rods," 2nd European Conference on Antennas and Propagation (EuCAP 2007), Edinburgh, 11-16 November 2007, pp. 1-5.

[17] X. Dong and T. An, "A New FEM Approach for Open Boundary Laplace's Problem," IEEE Transactions on Microwave Theory and Techniques, Vol. 44, No. 1, January 1996, pp. 157-160.

[18] X. Zhou and G. W. Pan, "Application of Physical Spline Finite Element Method (PSFEM) to Full Wave Analysis of Waveguide," Progress in Electromagnetic Research B, PIER, Vol. 60, 2006, pp. 19-41.

[19] J. L. Volakis, A. Chatterjee and L. C. Kempel, "Finite Element Method for Electromagnetic: Antennas, Microwave Circuits, and Scattering Applications," IEEE Press, Piscataway, 1998. 
[20] C. Mattiussi, "A Reference Discretization Strategy for the Numerical Solution of Physical Field Problems," $A d$ vances in Imaging and Electron Physics, Vol. 121, 2002, pp. 144-211. doi:10.1016/S1076-5670(02)80027-1

[21] A. C. Polycarpou, "Introduction to Finite Element Method in Electromagnetics," Morgan \& Claypool Publishers' Series, Waterloo, 2006.

[22] Z. Chen and M. Ney, "The Method of Weighted Residuals: A General Approach to Deriving Time and Frequency Domain Numerical Methods," IEEE Antennas and Propagation Magazine, Vol. 51, No. 1, February 2009, pp. 51-70. doi:10.1109/MAP.2009.4939019

[23] D. Jiao, M. Lu, E. Michielssen and J. Jin, "A Fast Time-Domain Finite Element-Boundary Integral Method for Electromagnetic Analysis," IEEE Antennas and Propagation Magazine, Vol. 49, No. 10, October 2001, pp. 1453-1461. doi:10.1109/8.954934

[24] A. Mitchell, D. M. Kokotoff and M. W. Austin, "Improvement to the PML Boundary Condition in the FEM Using Mesh Compression," IEEE Transactions on Microwave Theory and Techniques, Vol. 50, No. 5, May 2002, pp. 1297-1302. doi:10.1109/22.999142

[25] T. Weiland, "A Discretization Method for the Solution of Maxwell's Equations for Six-Component Fields," Electronics and Communications, AEU, Vol. 31, No. 3, March 1977, pp. 116-120.
[26] I. Munteanu1 and T. Weiland, "RF \& Microwave Simulation with the Finite Integration Technique-From Component to System Design," Scientific Computing in Electrical Engineering Mathematics in Industry, Part III, Vol. 11, 2007, pp. 247-260.

[27] G. Benderskaya, "Numerical Methods for Transient Field-Circuit Coupled Simulations Based on the Finite Integration Technique and a Mixed Circuit Formulation," Ph. D. Thesis, Technischen Universitat Darmstadt, Darmstadt, 2007.

[28] U. van Rienen, "Frequency Domain Analysis of Waveguides and Resonators with FIT on Non-Orthogonal Triangular Grids," Progress in Electromagnetics Research (PIER), Vol. 32, 2001, pp. 357-381. doi:10.2528/PIER00080114

[29] A. Monorchio, A. R. Bretones, R. G. Martin, G. Manara and R. Mittra, "A Hybrid Time Domain Technique Combining the Finite Element, Finite Difference and Integral Equation Methods," In Proceedings IEEE Antenna and Propagation Society International Symposium, Salt Lake City, Vol. 2, 2000, pp. 733-736.

[30] S. M. Rao, G. K. Gothard and D. R. Wilton, "Application of Finite-Integral Technique to Electromagnetic Scattering by Two-Dimensional Cavity-Backed Aperture in a Ground Plane," IEEE Transactions on Antennas and Propagation, Vol. 46, No. 5, May 1998, pp. 679-685. doi: $10.1109 / 8.668911$ 